\title{
PROTOTYPE REKAPITULASI DATA PADA APLIKASI JASA PENGIRIMAN BERBASIS ONLINE
}

\author{
Rusdina \\ Fakultas Teknologi Informasi, Universitas Islam Kalimantan MAB Banjarmasin \\ Email : russidina@gmail.com
}

\begin{abstract}
Abstrak
Sebagai salah satu penyedia jasa pengiriman di kota Banjarmasin yang sudah padat penduduk nya, $B$ kurir membutuhkan sebuah sistem yang dapat merekapitulasi data dengan lebih cepat dan akurat. Penelitian ini mengunakan model prototype untuk membuat aplikasi jasa pengiriman berbasis online terutama untuk rekapitulasi data pengiriman yang selama ini dilakukan secara semi komputerisasi / konvensional. Dengan membangun model prototyping yang mengutamakan komunikasi dengan calon pengguna / objek penelitian, tentunya aplikasi cepat diselesaikan dan diimplementasikan kepada objek.
\end{abstract}

Keyword : Aplikasi, Online, Prototype

\section{PENDAHULUAN}

Jasa pengiriman barang merupakan kegiatan yang meliputi proses pengiriman dan pengambilan barang dari satu tempat ke tempat lain. Perkembangan jasa kurir atau pengiriman barang dan logistik di Indonesia saat ini semakin berkembang pesat. Hal tersebut dikarenakan kebutuhan konsumen dalam hal pengiriman barang semakin tinggi. Dalam perkembangannya kurir sekarang tidak hanya untuk mengantar barang, belanjaan dan juga bisa memesan tiket bioskop, biaya yang dibayar pun terbilang cukup murah. Dalam perkembangannya, jasa pengantaran barang secara daring pun mulai marak bermunculan di Kota Banjarmasin, salah satunya yaitu BKurir Banjarmasin. BKurir Banjarmasin merupakan jasa transportasi roda dua yang memberikan layanan antar jemput barang (kurir) yang beroperasi di wilayah Banjarmasin, Banjar dan Banjarbaru. Jasa yang ditawarkan Bright Kurir yaitu antar jemput barang atau dokumen, pesanan belanjaan, dan pemesanan tiket bioskop.

BKurir Banjarmasin merupakan tempat penulis melakukan penelitian. Berdasarkan temuan dari penulis selama melakukan penelitian di lapangan, terdapat beberapa masalah yang ada pada BKurir Banjarmasin yaitu salah satunya adalah pemesanan jasa pada BKurir masih menggunakan media sosial dan website resmi juga belum ada, oleh sebab itu belum banyak masyarakat yang mengetahui informasi tentang BKurir Banjarmasin. Lalu untuk admin Bkurir mengelola data kurir, data konsumen, data transaksi dan laporan-laporan masih menggunakan sistem manual, yaitu dengan pembukuan yang masih tertulis. Jumlah orderan pada BKurir Banjarmasin masih dapat dibilang tidak terlalu banyak, ratarata hanya 40 order per bulan. Seiring berjalannya waktu akan semakin banyak pelanggan yang memakai jasa BKurir Banjarmasin, tentunya akan semakin banyak juga data yang harus disimpan sehingga memerlukan tempat yang lebih untuk penyimpanan data tersebut. Penggunaan sistem manual memiliki beberapa kekurangan baik dari segi waktu yang kurang efisien dan segi penyimpanan data yang masih memiliki kekurangan yaitu rentan hilang karena hanya dilakukan tertulis.

Sejumlah penelitian yang menjadi referensi diantaranya "Pembuatan Aplikasi Jasa Ekspedisi Berbasis Web pada CV. Lima Jaya Surabaya, Jawa Timur" oleh Nova Prista La Adisamu pada tahun 2014 dengan permasalahan dalam proses bisnisnya masih menggunakan sistem manual dalam melakukan transaksi dengan pelanggan. Kemudian terjadinya penumpukan tugas pada kasir sehingga berpotensi terjadinya human error seperti kesalahan pembuatan laporan, pengiriman dan penerimaan barang atau merekap data pengiriman barang sehingga menghabiskan waktu yang cukup lama. 
Kemudian pada penelitian Jurike Moniaga pada tahun 2012 yang berjudul "Analisis dan Pengembangan Jasa Pengiriman Barang berbasis Web pada PT. CCS Logistics" memiliki permasalahan sulitnya admin dalam memberikan info pada konsumen mengenai status kiriman dan info biaya pengiriman. Sedangkan pada penelitian "Sistem Informasi Tiket Bioskop Pada Buaran Teater di Jakarta Timur Berbasis Web" dengan permasalahan yaitu sistem pemesan tiket yang saat ini berjalan kurang efektif dan tidak efisien karena hanya menggunakan sistem manual yang dapat mengakibatkan kesalahan, antiran yang cukup panjang, dan efisiensi waktu. Oleh karena itu, berdasarkan dari permasalahan yang ada pada BKurir Banjarmasin, penulis ingin menganalisa sebuah aplikasi yang mampu mempermudah proses pengaksesan informasi dan transaksi pemesanan pada BKurir Banjarmasin.

\section{RUMUSAN DAN BATASAN MASALAH}

Beberapa rumusan permasalahan penelitian diidentifikasi sebagai berikut :

1. Pemesanan yang dilakukan masih melalui perpesanan instan, sehingga sulit untuk mendeteksi pesanan yang telah diproses.

2. Belum ada aplikasi yang menunjang kinerja admin mengenai pendataan pesanan serta pembuatan laporan.

3. Untuk promosi jasa pengiriman ini masih menggunakan sosial media sehingga masyarakat masih sulit mengetahui.

Sedangkan batasan masalah nya mencakup:

1. Penelitian hanya membahas tentang jasa pengantaran pada BKurir Banjarmasin dan pengelolaan data oleh admin Bkurir.

2. Pembuatan aplikasi yang dilakukan sebatas pada proses pemesanan jasa dan memanajemen data pesanan pada BKurir Banjarmasin.

3. Jenis jasa yang bisa diorder meliputi pengantaran barang atau dokumen, pemesanan belanjaan dan tiket bioskop.

4. Aplikasi yang dibuat masih belum memiliki fitur pelacakan pesanan berbasis posisi (GPS).

5. Penggunaan pada level kurir tidak disediakan fitur pembatalan pesanan begitupun untuk pelanggan agar mengurangi potensi kesalahan pemesanan.

Dengan adanya penelitian ini diharapkan memberikan manfaat dalam hal :

1. Mempermudah masyarakat untuk memperoleh informasi mengenai jasa pengantaran barang pada BKurir Banjarmasin, khususnya masyarakat Kota Banjarmasin, Banjar dan Banjarbaru.

2. Mempermudah proses dan transaksi yang berjalan di BKurir, dengan lancarnya proses dan transaksi pada BKurir maka dapat menambah pelanggan

3. Mempermudah owner dan admin dalam mengelola data, transaksi, dan pelanggan BKurir Banjarmasin.

\section{MEMBANGUN PROTOTYPING DALAM METODE PENELITIAN}

Dalam metode atau model prototyping, di lakukan beberapa langkah utama yaitu menganalisa kebutuhan, seperti yang sudah dituangkan pada bab sebelumnya, kemudian Membangun prototyping yaitu membuat perancangan sementara yang berfokus pada penyajian objek penelitian . lalu mengevaluasi prototype, dan membuat prototype aplikasi kemudian mengujinya . Berikut Rancangan Diagram yang dibuat pada prototype aplikasi :

Use Case Diagram 


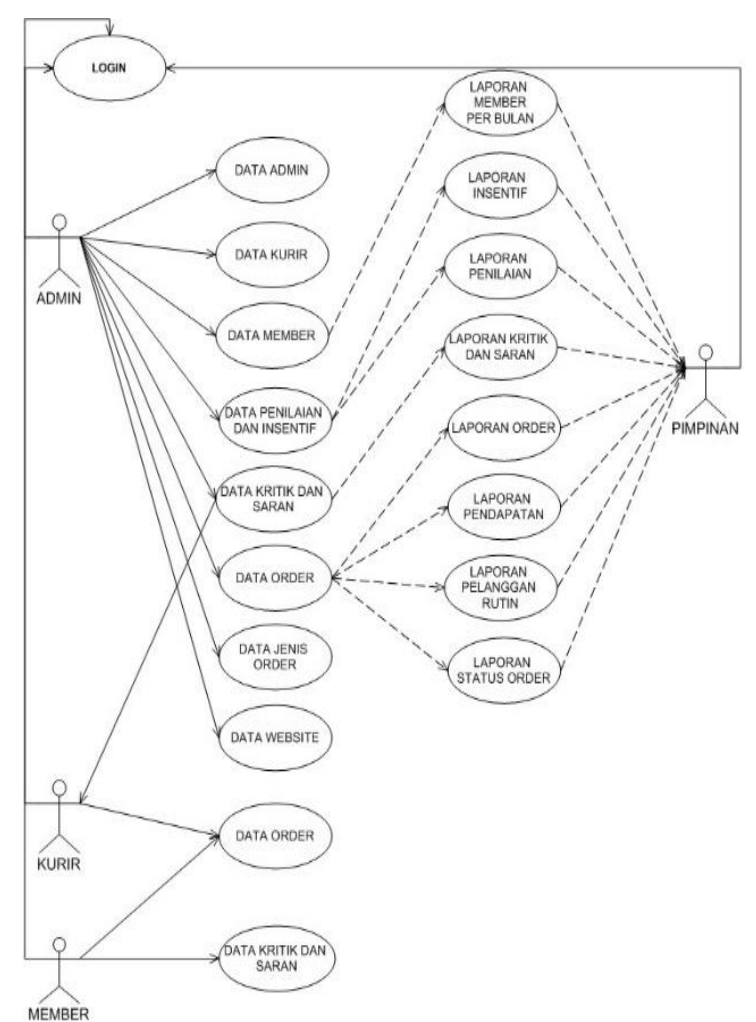

Gambar 1. Usecase Diagram yang dibuat pada program

Aplikasi yang dibuat dengan model multiuser yaitu 4 (empat) user. User nya yaitu Admin , Kurir, Member, dan Pimpinan. Metode input ke aplikasi sesuai dengan yang ada pada gambar di atas. Untuk mengetahui alur protoype diagram, maka perlu dibuat skenario. Berikut skenario usecase yang sudah dibuat untuk prototype aplikasi :

Skenario Use Case Diagram

Tabel 1. Skenario Data Admin

\begin{tabular}{ll} 
Nama Use Case & Data Admin \\
Aktor yang terlibat & Admin \\
Trigger & Admin menambah, ubah dan hapus data admin \\
\hline Pre Condition & Data pada tabel admin \\
\hline Action & Simpan, Ubah dan Hapus Data Admin \\
\hline Post Condition & Data admin dikelola sesuai keinginan Aktor \\
\hline
\end{tabular}

Tabel 2. Skenario Data Kurir

\begin{tabular}{lll} 
& \multicolumn{2}{c}{ Skenario Data Kurir } \\
\hline Nama Use Case & Data Kurir \\
\hline Aktor yang terlibat & Admin \\
\hline Trigger & Admin menambah, ubah dan hapus Data Kurir \\
\hline Pre Condition & Data pada tabel kurir \\
\hline Action & Simpan, Ubah dan Hapus Data Kurir \\
\hline Post Condition & Data kurir dikelola sesuai keinginan Aktor \\
\hline
\end{tabular}

Tabel 3. Skenario Data Member

\begin{tabular}{ll}
\hline Nama Use Case & Data Member \\
\hline Aktor yang terlibat & Member, Admin \\
\hline Trigger & Aktor menambah, ubah dan hapus Data Member \\
\hline Pre Condition & Data pada tabel member \\
\hline Action & Simpan, Ubah dan Hapus Data Member \\
\hline Post Condition & Data member dikelola sesuai keinginan Aktor \\
\hline
\end{tabular}

Tabel 4. Skenario Data Order

\begin{tabular}{ll} 
& \multicolumn{1}{c}{ Skenario Data Order } \\
\hline Nama Use Case & Data Order \\
Aktor yang terlibat & Member, Kurir, Admin \\
\hline Trigger & Aktor menambah, ubah dan hapus data order \\
\hline Pre Condition & Data pada tabel order \\
\hline Action & Simpan, Ubah, dan Hapus data Order \\
\hline Post Condition & Data Order dikelola sesuai keinginan Aktor \\
\hline
\end{tabular}

Selanjutnya adalah Activity Diagram. Berikut adalah activity diagram aplikasi yang dibuat : 


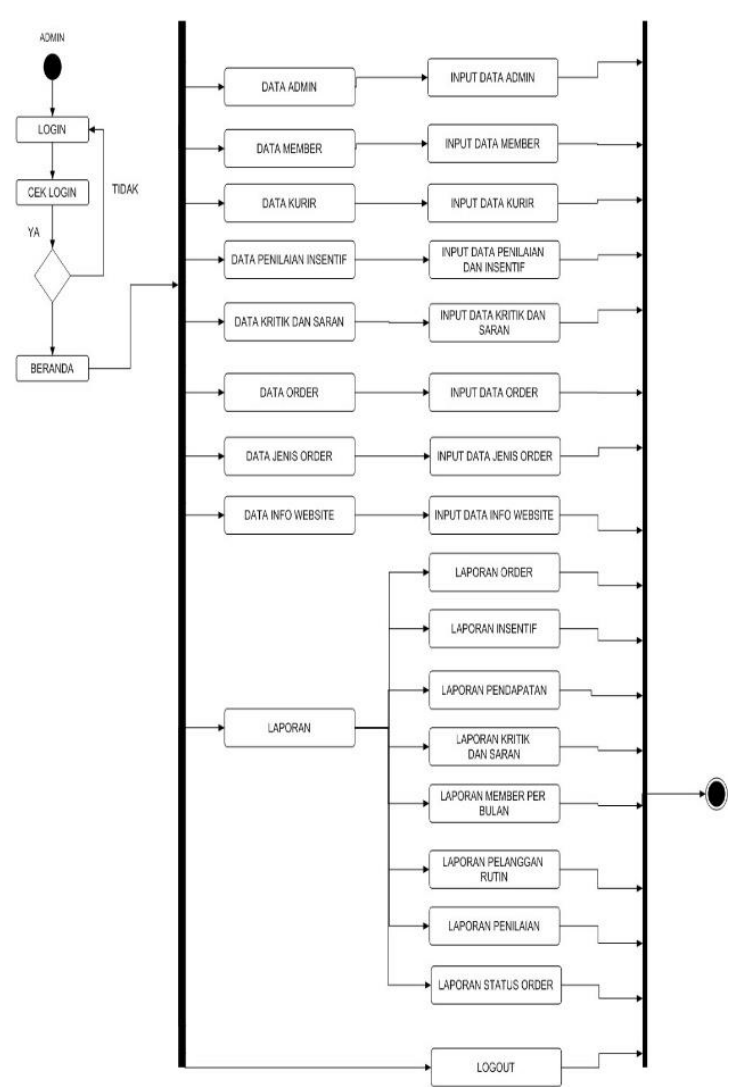

Gambar 2. Activity Diargam User Admin

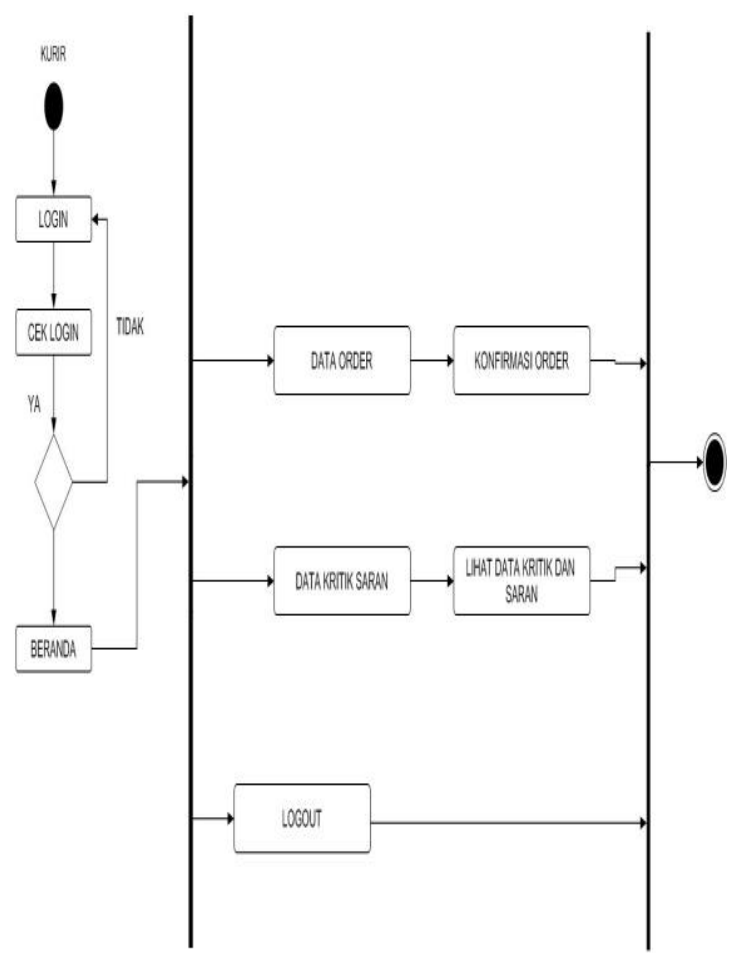

Gambar 3. Activity Diagram User Kurir

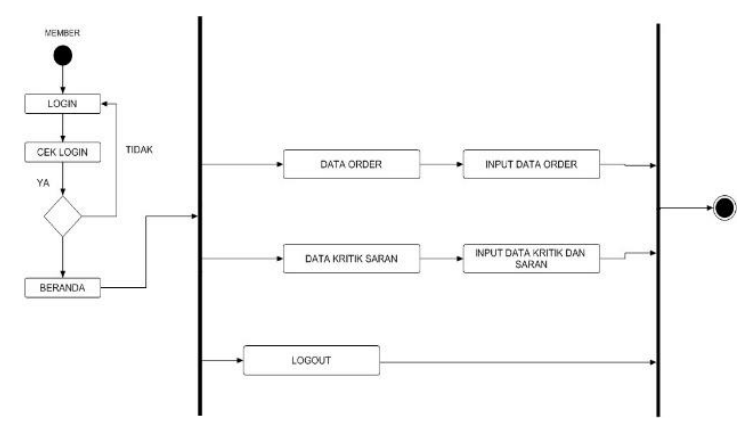

Gambar 4. Activity Diagram User Member

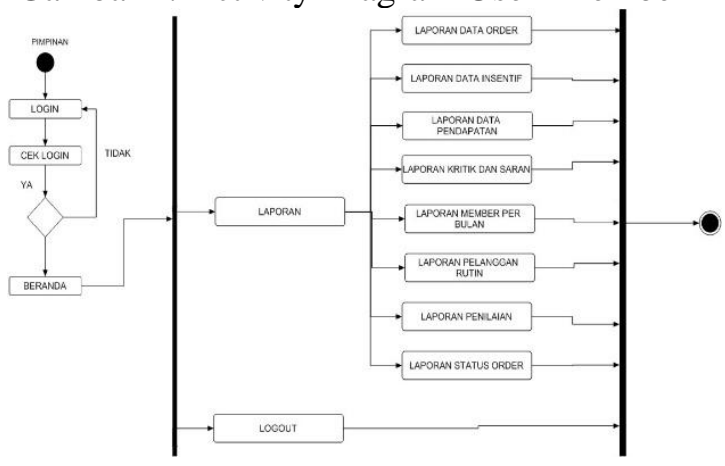

Gambar 5 Activity Diagram user Pimpinan

\section{MENGKODEKAN SISTEM MENJADI APLIKASI}

Tampilan dibawah merupakan beberapa tampilan untuk Halaman Utama website. Disana terdapat informasi lengkap mengenai Bright Kurir Banjarmasin seperti info harga, dan layanan yang ditawarkan.

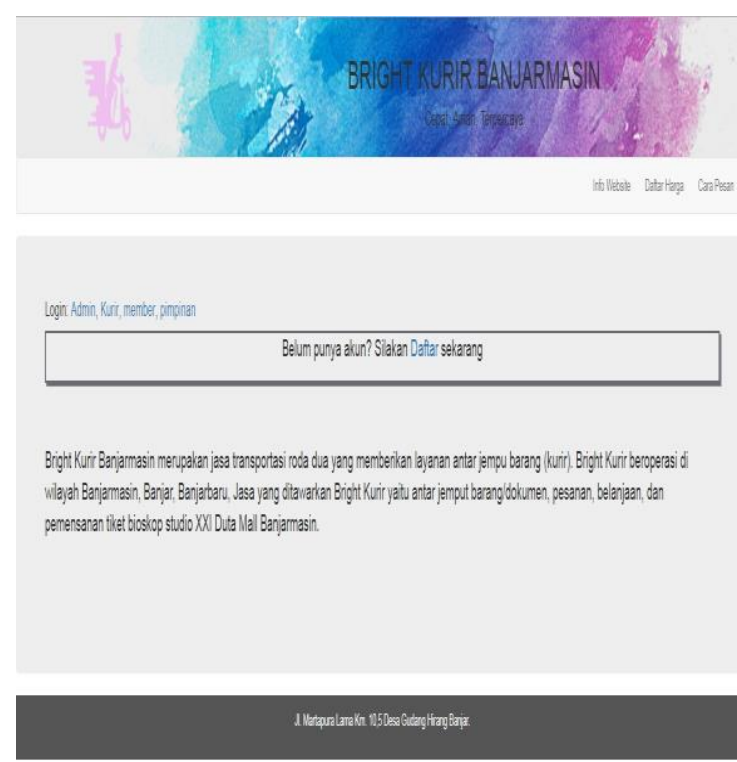

Gambar 6 Tampilan Beranda Aplikasi Kurir 


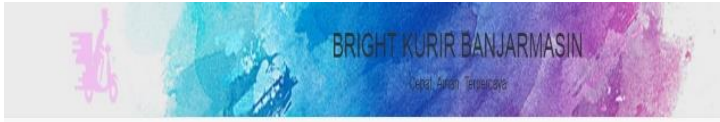

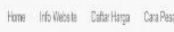

\section{INFOWEBSTE}

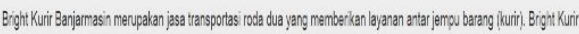

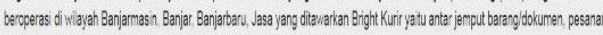

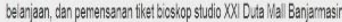

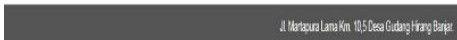

Gambar 7 Informasi Website

Halaman daftar harga. Halaman ini berisikan daftar harga, rute, wilayah dari layanan jasa bright kurir ini

BRIGHT KLRIR BANJARMLASIN

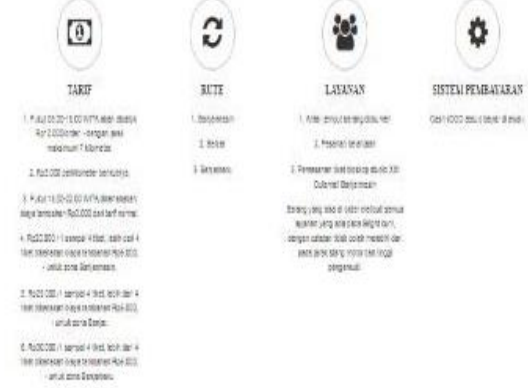

Gambar 8 Halaman Daftar Harga

Selain tampilan tersebut, Berikut tampilan antar muka user admin

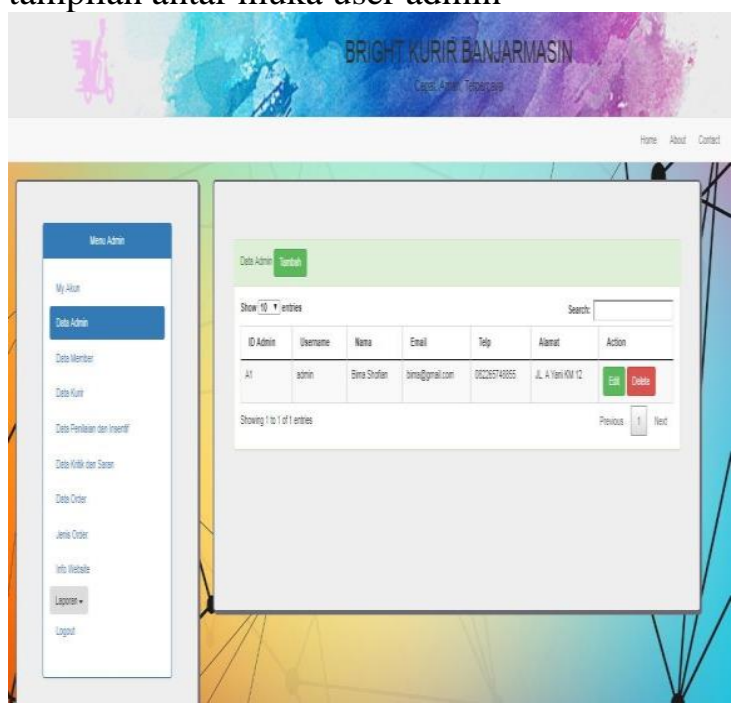

Gambar 9 Tampilan user Admin Tampilan antar muka user kurir

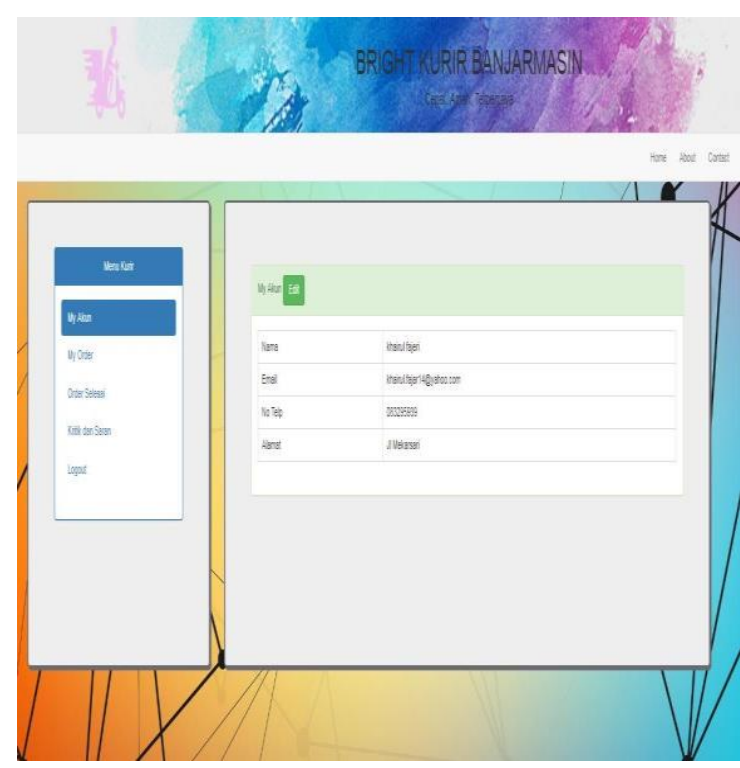

Gambar 10 Tampilan User Kurir

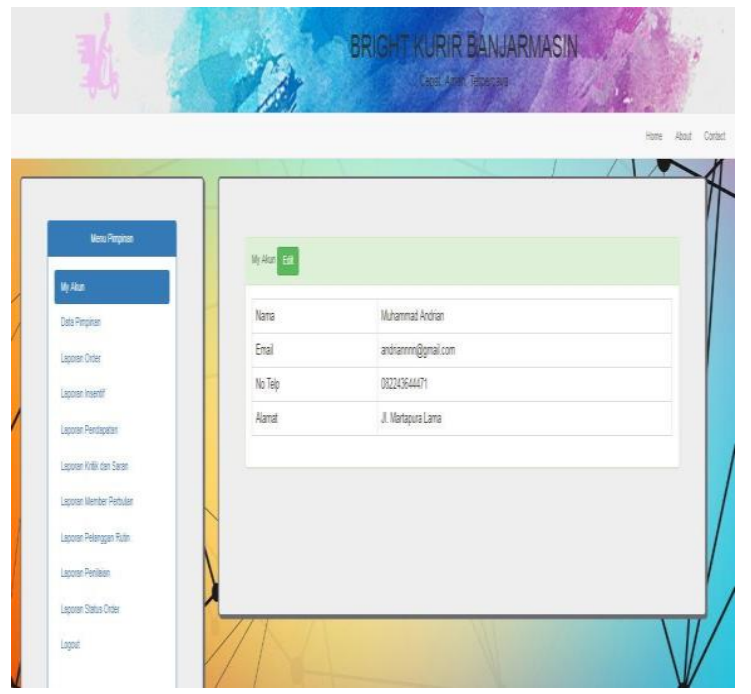

Gambar 11 Tampilan User Pimpinan

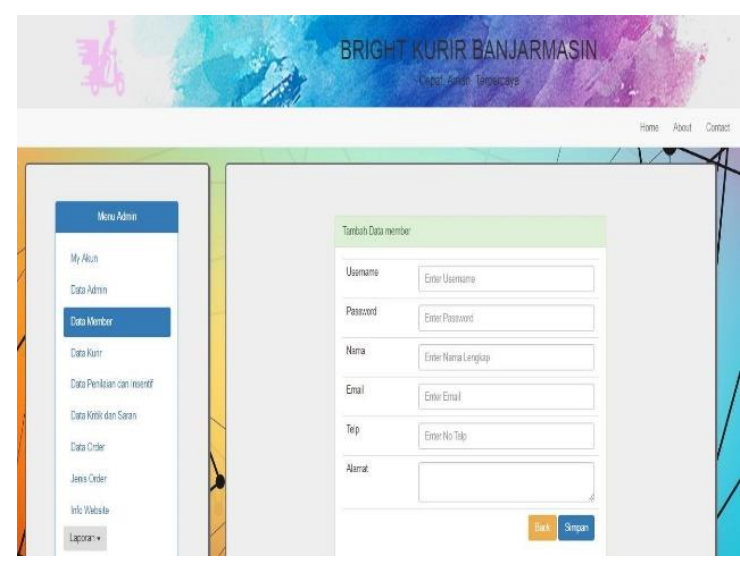




\section{Gambar 12 Tampilan Data Member}

Untuk output aplikasi berupa laporan order bulanan, laporan insentif kurir, laporan pendapan atau laba, kritik dan saran konsumen , laporan member perbulan, laporan member rutin, lporan penilaian, dan laporan status order .

\section{PENGUJIAN SISTEM}

Untuk Pengujian sistem kami menggunakan Whitebox dan blackbox.

Tabel 5 Skema Sistem Admin (whitebox)

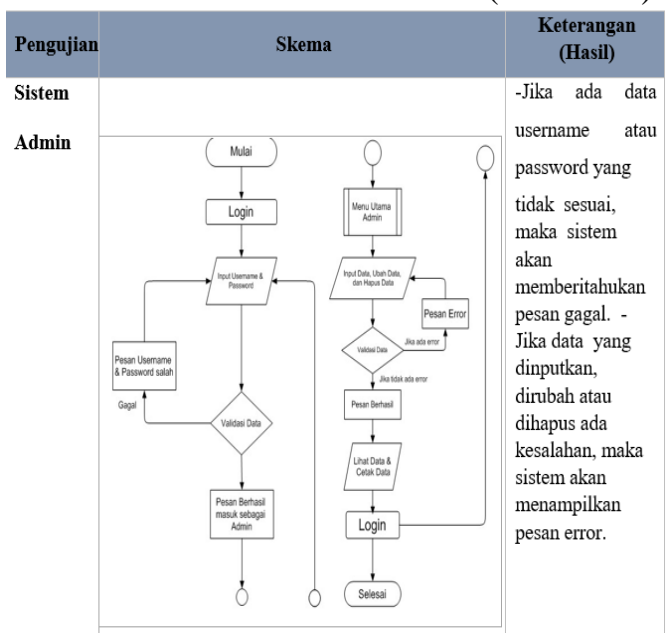

Tabel 6 Pengujian Blackbox

\begin{tabular}{|l|l|l|}
\hline $\begin{array}{l}\text { Pengolahan } \\
\text { Data } \\
\text { Admin }\end{array}$ & $\begin{array}{l}\text { Add Data } \\
\text { Simpan Data Admin } \\
\text { Ubah Data Admin } \\
\text { Hapus Data Admin }\end{array}$ & $\begin{array}{l}\text { Blackbox } \\
\text { Blackbox } \\
\text { Blackbox } \\
\text { Blackbox }\end{array}$ \\
\hline $\begin{array}{l}\text { Pengolahan } \\
\text { Data } \\
\text { Member }\end{array}$ & Add Data & Blackbox \\
& Simpan Data Member & Blackbox \\
& Ubah Data Member & Blackbox \\
& Hapus Data Member & Blackbox \\
Cetak Data Member & Blackbox \\
\hline $\begin{array}{l}\text { Pengolahan } \\
\text { Data }\end{array}$ & Add Data & Blackbox \\
Pimpinan & Simpan Data Pimpinan & Blackbox \\
& Ubah Data Pimpinan & Blackbox \\
& Hapus Data Pimpinan & Blackbox \\
\hline $\begin{array}{l}\text { Pengolahan } \\
\text { Data Kurir }\end{array}$ & Add Data & Blackbox \\
& Simpan Data Kurir & Blackbox \\
& Ubah Data Kurir & Blackbox \\
& Hapus Data Kurir & Blackbox \\
\hline Pengolahan & Add Data & Blackbox \\
Data Order & Simpan Data Order & Blackbox \\
& Ubah Data Order & Blackbox \\
& Hapus Data Order & Blackbox \\
& Cetak Data Order & Blackbox \\
& Cari Data Order & Blackbox \\
\hline
\end{tabular}

\begin{tabular}{|c|c|c|}
\hline $\begin{array}{l}\text { Pengolahan } \\
\text { Data Jenis } \\
\text { Order }\end{array}$ & $\begin{array}{l}\text { Add Data } \\
\text { Simpan Data Jenis Order } \\
\text { Ubah Data Jenis Order } \\
\text { Hapus Data Jenis Order } \\
\text { Cari Data Jenis Order }\end{array}$ & $\begin{array}{l}\text { Blackbox } \\
\text { Blackbox } \\
\text { Blackbox } \\
\text { Blackbox } \\
\text { Blackbox } \\
\end{array}$ \\
\hline $\begin{array}{l}\text { Pengolahan } \\
\text { Data } \\
\text { Register }\end{array}$ & $\begin{array}{l}\text { Add Data } \\
\text { Simpan Data Register } \\
\text { Ubah Data Register } \\
\text { Hapus Data Register } \\
\text { Cetak Data Register } \\
\text { Cari Data Register }\end{array}$ & $\begin{array}{l}\text { Blackbox } \\
\text { Blackbox } \\
\text { Blackbox } \\
\text { Blackbox } \\
\text { Blackbox } \\
\text { Blackbox }\end{array}$ \\
\hline $\begin{array}{l}\text { Pengolahan } \\
\text { Data Kritik } \\
\text { dan } \\
\text { Saran }\end{array}$ & $\begin{array}{l}\text { Add Data } \\
\text { Simpan Data Kritik dan } \\
\text { Saran } \\
\text { Hapus Data Kritik dan } \\
\text { Saran } \\
\text { Cetak Data Kritik dan } \\
\text { Saran } \\
\end{array}$ & $\begin{array}{l}\text { Blackbox } \\
\text { Blackbox } \\
\text { Blackbox } \\
\text { Blackbox }\end{array}$ \\
\hline
\end{tabular}

\section{KESIMPULAN}

Aplikasi Rekapitulasi Data Jasa Pengiriman Berbasis Online lebih mudah di aplikasikan karena menggunakan model prototyping yang mempunyai kelebihan yaitu langsung mengetahui apa keinginan pengguna yaitu objek penelitian dan langsung diimplementasikan ke aplikasi. Aplikasi yang dibuat memudahkn rekapitulasi data dalam pengiriman menggunakan jasa pengiriman online.

\section{REFERENSI}

[1] Abdul, K. (2003). Pengenalan sistem informasi. Yogyakarta: Andi.

[2] Adisamu, N. P. (2014). Pembuatan Aplikasi Jasa Ekspedisi Berbasis Web pada CV. Lima Jaya Surabaya, Jawa Timur .

[3] Bahtiar, A. (2011). Rancang Bangun Aplikasi Nilai Siswa Akademik Sekolah Berbasis Web SMA Asshidiqiyah II Tangerang. Jakarta: Universitas Islam Negeri Syarief Hidayatullah.

[4] Rina Alfah, T. V. R., 2018. Sistem EPrescribing Dan BARCODE SYSTEM Untuk Resep Obat Di Rumah Sakit. Jurnal Teknologi Informasi Universitas Lambung Mangkurat (JTIULM), 03(Vol. 3 No. 2 (2018)), pp. 59-70.

[5] Guritno, S., Sudaryono, \& Untung, R. (2011). Theory and Application of IT Research Metodologi Penelitian Teknologi Informasi. Yogyakarta: CV ANDI OFFSET.

[6] Hasibuan, Z. A. (2007). Metodologi Penelitian Pada Bidang Ilmu Komputer dan Teknologi Informasi. Jakarta. 
[7] Moniaga, J. (2012). Analisis dan Pengembangan Jasa Pengiriman Barang berbasis Web pada PT. CCS Logistics

[8] Rosa, A., \& Shalahuddin, M. (2015). Rekayasa Perangkat Lunak, Terstruktur dan Berorientasi Objek. Bandung: INFORMATIKA.

[9] Rusdina, 2018. Perancangan Aplikasi Rawat Inap Di Klinik Bidan Sumirat, Pengaron Kalimantan Selatan. Balikpapan, Seminar Nasional Teknologi Informasi, Komunikasi Dan Administrasi (Seminastika) Universitas Mulia Balikpapan

[10] Sudaryono. (2015). Metodologi Riset diBidang TI (Panduan Praktis, Teori dan Contoh Kasus). Yogyakarta: CV ANDI OFFSET. 